NBER WORKING PAPER SERIES

\title{
MULTIPLE-SOLUTION INDETERMINACIES \\ IN MONETARY POLICY ANALYSIS
}

\author{
Bennett T. McCallum \\ Working Paper 9837 \\ http://www.nber.org/papers/w9837 \\ NATIONAL BUREAU OF ECONOMIC RESEARCH \\ 1050 Massachusetts Avenue \\ Cambridge, MA 02138 \\ July 2003
}

This paper was prepared for the Carnegie-Rochester Conference on Public Policy, held at Carnegie Mellon University on November 22-23, 2002. For helpful comments and suggestions, I am indebted to George Evans, Marvin Goodfriend, Edward Nelson, and Michael Woodford. The views expressed herein are those of the authors and not necessarily those of the National Bureau of Economic Research

(C)2003 by Bennett T. McCallum. All rights reserved. Short sections of text not to exceed two paragraphs, may be quoted without explicit permission provided that full credit including (C) notice, is given to the source. 
Multiple-Solution Indeterminacies in Monetary Policy Analysis

Bennett T. McCallum

NBER Working Paper No. 9837

July 2003

JEL No. E3, E5, C6

\section{$\underline{\text { ABSTRACT }}$}

This paper discusses four current topics in monetary policy analysis, each of which hinges on the possibility of multiple solutions in rational expectations (RE) models. In three of these cases--involving inflation forecast targeting, the zero-lower bound deflation trap, and the fiscal theory of the price level-analysis based on E-stability and adaptive learnability of the solutions suggests that only one of them is a viable equilibrium candidate. Thus the dangers alleged to prevail, in these cases, are not ones with which actual policymakers need to be concerned. In the case of the Taylor principle, by contrast, policy behavior that violates the principle is genuinely undesirable, since all of the RE equilibria fail to be learnable.

Bennett T. McCallum

Graduate School of Industrial Administration

Carnegie Mellon University

Pittsburgh, PA 15213

and NBER

bmccallum@cmu.edu 


\section{$\underline{\text { 1. Introduction }}$}

A sizeable fraction of recent research on monetary policy has been concerned with issues relating to analytical "indeterminacies"-i.e., multiple solutions in rational expectations (RE) models. Prominent topics for which this type of indeterminacy is central to the analysis include (i) the "Taylor principle" [Clarida, Gali, and Gertler (1999, 2000), King (2000), Woodford (2001)]; (ii) inflation forecast targeting [Woodford (1994, 2002), Bernanke and Woodford (1996), Kerr and King (1996), Carlstrom and Fuerst (2001), Bullard and Mitra (2002)]; (iii) the zero-lower-bound deflation trap [Benhabib, Schmitt-Grohe, and Uribe (2001, 2002), Alstadheim and Henderson (2002)], and (iv) the fiscal theory of the price level [Woodford (1994, 1995, 2002), Sims (1994), Cochrane (1998), Kocherlakota and Phelan (1999)]. The papers just mentioned, moreover, include only a sample of leading items, not an exhaustive listing. Most of the literature features sophisticated RE analysis conducted within dynamic models that reflect optimizing behavior by individual agents and incorporate Taylor-style policy rules.

A few papers have suggested that some of the particular indeterminacy arguments are misleading or irrelevant; these include Buiter (1999) and McCallum (1999b, 2001a, 2001b). For the most part, however, there has been little dissent from the position that these indeterminacies present a genuine problem for monetary policy makers. The purpose of the present paper, by contrast, is to argue that conclusions based on multiplesolution indeterminacy findings are of dubious merit rather generally. In each of the mentioned cases, that is, there is at most one RE solution that should be regarded as plausible, the others reflecting theoretical curiosities that are not of relevance for actual economies. As it happens, the plausible solution in most or all of the cases studied is the 
minimum-state-variable (MSV) solution defined in McCallum (1983, 1999b), which is unique by construction in linear models. The principle basis of the argument developed here depends, however, not on any alleged "fundamental" or "bubble-free" nature of the MSV solution, but on the E-stability and adaptive learnability of this solution as defined and explored in important recent publications by Evans and Honkapohja (1999, 2001).

The outline of the paper is as follows. In Section 2, two preliminary issues of a partly terminological but also substantive nature are taken up, so as to avoid ambiguity or confusion later in the discussion. Next, Section 3 provides a brief summary of the E-stability/ least-squares learnability approach and includes a brief argument for its importance. Then in Sections 4-7 the four topics mentioned above are considered in turn, with each presented in the simplest possible setting. Finally, a short concluding section is provided.

\section{Preliminaries}

There are two partly terminological issues that should be confronted at the outset, so as to avoid ambiguities based on different implicit definitions. The first of these is the nature of the MSV solution. Throughout, I will be using that term to designate the solution yielded by the procedure of McCallum (1983, 1999b), which is designed to be unique by construction. This terminological usage agrees with that of Evans (1986, 1989) and Evans and Honkapohja (E\&H) (1992) but differs from that employed in the latter's more recent publications (E\&H, 1999, p. 496; 2001, p. 194). Either terminology could be used, of course, but the one adopted here is more appropriate and convenient for the issues at hand.

To clarify the distinction, consider first the univariate model 


$$
\mathrm{y}_{\mathrm{t}}=\alpha+\mathrm{aE}_{\mathrm{t}} \mathrm{y}_{\mathrm{t}+1}+\mathrm{cy}_{\mathrm{t}-1}+\mathrm{u}_{\mathrm{t}},
$$

where $\mathrm{a} \neq 0$ and $\mathrm{u}_{\mathrm{t}}=\rho \mathrm{u}_{\mathrm{t}-1}+\varepsilon_{\mathrm{t}}$ with $|\rho|<1$ and $\varepsilon_{\mathrm{t}}$ being white noise. Then the usual listing of relevant state variables (i.e., determinants of $y_{t}$ ) would include just $y_{t-1}$ and $u_{t}$ (plus a constant term), so the MSV solution will be of the form

$$
\mathrm{y}_{\mathrm{t}}=\phi_{0}+\phi_{1} \mathrm{y}_{\mathrm{t}-1}+\phi_{2} \mathrm{u}_{\mathrm{t}}
$$

which includes no extraneous state variables and in which $\phi_{0}, \phi_{1}$, and $\phi_{2}$ are restricted to be real. This implies that $\mathrm{E}_{\mathrm{t}} \mathrm{y}_{\mathrm{t}+1}=\phi_{0}+\phi_{1}\left(\phi_{0}+\phi_{1} \mathrm{y}_{\mathrm{t}-1}+\phi_{2} \mathrm{u}_{\mathrm{t}}\right)+\phi_{2} \rho \mathrm{u}_{\mathrm{t}}$ and substitution into (1) requires that the $\phi_{\mathrm{j}}$ coefficients must satisfy the following conditions:

$$
\begin{aligned}
& \phi_{0}=\alpha+a \phi_{0}+a \phi_{1} \phi_{0} \\
& \phi_{1}=\mathrm{a} \phi_{1}^{2}+\mathrm{c} \\
& \phi_{2}=\mathrm{a} \phi_{1} \phi_{2}+\mathrm{a} \rho \phi_{2}+1 .
\end{aligned}
$$

Clearly, the second of these conditions yields two potential values for $\phi_{1}$, namely, $[1 \pm \sqrt{1-4 a c}] / 2 a$. These represent two different functions of a and c, say $\phi_{1}^{(+)}$and $\phi_{1}^{(-)}$, which therefore define two different RE solutions. In what sense, then, is there a unique MSV solution? By definition, it is the one that includes no extraneous state variable for any relevant value of a and c. In other words, extraneous state variables are excluded for all values of $\mathrm{a}$ and $\mathrm{c}$ in broad open sets that include $\mathrm{a}=0$ and $\mathrm{c}=0$. Thus the MSV solution will be the one provided by use of the $\phi_{1}^{(-)}$root, because it is the one that implies $\phi_{1}=0$ in cases in which $\mathrm{c}=0 .{ }^{1} \quad\left(\right.$ Use of $\phi_{1}^{(+)}$would give $\phi_{1}=1 / \mathrm{a}$ in these cases, even though $\mathrm{y}_{\mathrm{t}-1}$ does not appear in the model .) Then with $\phi_{1}$ uniquely determined, the values

\footnotetext{
${ }^{1}$ In the very unlikely case that $\phi_{1}^{(+)}$and $\phi_{1}^{(-)}$both equal 0 at $\mathrm{c}=0$, then the one with a continuous first derivative would be designated as $\phi_{1}$ for the MSV solution.
} 
of $\phi_{0}$ and $\phi_{2}$ are given unambiguously by $(3 a)$ and $(3 c)$. Evans $(1986,1989)$ termed this the MSV solution — indeed, he coined the term — whereas E\&H $(1999,2001)$ refer to both of the solutions of form (2) as MSV solutions (with non-MSV solutions also including terms such as $\mathrm{y}_{\mathrm{t}-2}$ and $\mathrm{u}_{\mathrm{t}-1}$, as well as "sunspot" variables unrelated to the model).

The same type of procedure applies in multivariate linear models. Suppose that the model includes a $\mathrm{m} \times 1$ vector $\mathrm{y}_{\mathrm{t}}$ of endogenous variables, as in

$$
\mathrm{y}_{\mathrm{t}}=\mathrm{A} \mathrm{E}_{\mathrm{t}} \mathrm{y}_{\mathrm{t}+1}+\mathrm{C}_{\mathrm{t}-1}+\mathrm{u}_{\mathrm{t}}, \quad \mathrm{A} \neq 0
$$

where $\mathrm{u}_{\mathrm{t}}=\mathrm{Ru}_{\mathrm{t}-1}+\varepsilon_{\mathrm{t}}$ includes exogenous variables and shocks, with $\mathrm{R}$ a stable $\mathrm{m} \times \mathrm{m}$ matrix and $\varepsilon_{\mathrm{t}}$ a white noise vector. (Constant terms are absent for expositional purposes.) Then the MSV solution will be of the form

$$
\mathrm{y}_{\mathrm{t}}=\Omega \mathrm{y}_{\mathrm{t}-1}+\Gamma \mathrm{u}_{\mathrm{t}}
$$

There are many $\Omega$ matrices that will satisfy the quadratic matrix equation analogous to (3b), which is $\Omega=\mathrm{A} \Omega^{2}+\mathrm{C}$, but the MSV value is the one that equals 0 when $\mathrm{C}=0$. In most cases it will coincide with the one whose m eigenvalues are the smallest (in modulus). For additional discussion, see McCallum (1999b).

The second preliminary issue to be discussed involves the contention of McCallum (1986, 1999a, 2001b) that it is important to distinguish between two different types of indeterminacy, which may be referred to as nominal indeterminacy and multiple

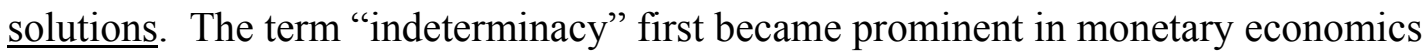
from a series of writings by Patinkin $(1949,1965)$ about an alleged logical inconsistency in classical monetary theory. Some of Patinkin's conclusions were disputed by Gurley and Shaw (1960) and the resulting controversy was reviewed in an influential survey article by Johnson (1962). In all of this earlier literature, it must be noted, the 
phenonmenon under discussion was "price level indeterminacy" such that the models in question fail to determine the value of any nominal variable, including the money supply. That type of failure occurs basically because of postulated policy behavior that is entirely devoid of any nominal anchor-i.e., there is no concern by the central bank for nominal variables. ${ }^{2}$ Since rational private households and firms care only about real variables, according to standard neoclassical analysis, the absence of any "money illusion" by them and by the central bank must imply that no agent (in the model) has any concern for any nominal variable. Thus there is in effect no nominal variable appearing anywhere in the model, so naturally it cannot determine the value of such variables.

The type of indeterminacy under discussion in the current monetary policy literature, with which the present paper is concerned, is very different. Instead of a failure to determine any nominal variable (with no implied problematic behavior for real variables), the recent literature is concerned with a multiplicity of stable equilibria in terms of real variables, typically with an exogenous path specified for some nominal variable. ${ }^{3}$ This type of aberrational behavior stems not from the absence of any nominal anchor (a static concept) but from the essentially dynamic fact that various paths of real variables can be consistent with rational expectations under certain conditions. In order to avoid possible semantic confusions, McCallum (1986) proposed that different terms be used for the two types of aberrational behavior-nominal indeterminacy and solution multiplicity, respectively. ${ }^{4}$ This proposal has not met with widespread acceptance,

\footnotetext{
${ }^{2}$ See Patinkin (1965, p. 309).

${ }^{3}$ It is dynamically stable equilibria that are most relevant, because explosive paths of real variables are often ruled out by transversality conditions that show them to be suboptimal for individual private agents.

4 The adjective "nominal" was omitted from my original proposal, but seems clearly to be desirable.
} 
although some writers are careful to refer to the second type as involving a "real indeterminacy."

Woodford (2002, Ch. 2, p. 50) has disputed the claim that it is important to distinguish between nominal indeterminacy and multiple solutions (or real indeterminacy). His argument is that a case of multiple solutions (from, e.g., an interest rate policy rule that fails to respect the Taylor principle) is not qualitatively different than the nominal indeterminacy that results (in a flexible price model) because the policy rule refers to no nominal variable at all, "even though in the latter special case it happens that the self-fulfilling expectations have no effect upon expected inflation, interest rates, or real balances" (2002, p. 50) - i.e., upon the model's real variables. I would suggest, however, that this "even though" proviso actually negates the argument being made. Second, Woodford goes on to say that "once we generalize our model to allow for staggered price setting" [i.e., sticky prices] "even a pure interest-rate peg ceases to result in 'nominal indeterminacy' ...." But the particular form of sticky prices that Woodford considers is such that the model continues to include nominal variables even when monetary policy supplies no nominal anchor, because private behavior involves a type of dynamic money illusion. ${ }^{5}$ If instead one incorporates sticky price adjustments of a type that respects the natural rate hypothesis, as in the P-bar model used by McCallum and Nelson (1999), then nominal indeterminacy will prevail if the monetary authority fails to provide a nominal anchor. ${ }^{6}$ Quite generally, nominal indeterminacy occurs if and only if

\footnotetext{
${ }^{5}$ Specifically, price adjustments are of the Calvo (1983) type, which does not conform to the natural rate hypothesis - see McCallum and Nelson (1999, pp. 26-27).

${ }^{6}$ The nominal indeterminacy will be basically of the type described in McCallum (1986, pp. 143-9), but with the words "price level" appearing instead of "money stock" in several places. Thus the model will not determine the absolute level of prices but will determine the expected inflation rate. Stochastic properties of the log price level will not be fully determined.
} 
the model includes only real variables whereas multiple-solution RE indeterminacy can occur only in dynamic RE models in which expectations of future endogenous variables appear. This distinction would seem to be of considerable theoretical importance since one concept involves multiple paths of real variables while the other does not, since one is dynamic and the other static, and since they stem from fundamentally different sources. $^{7}$ I agree entirely, however, with Woodford's apparent view that nominal indeterminacy is unlikely to be of importance in actual economies, since only a small degree of money illusion —on the part of either private agents or the monetary authority—will rule it out.

\section{E-stability and Least Squares Learnability}

In this section the object is to provide a short review of the concepts known as E-stability and LS learnability. Evans $(1985,1986)$, building upon a result of DeCanio (1979), initially developed iterative E-stability as a selection criterion for RE models with multiple solutions. The basic presumption is that individual agents will not be endowed with exact knowledge of the economic system's structure, so it must be considered whether plausible correction mechanisms are convergent. Consider, for example, model (1). The usual "fundamentals" RE solution will be of the form (2), as stated above, but suppose that agents do not initially know the true values of the $\phi_{\mathrm{j}}$ parameters. If at any date $t$ the agents' prevailing belief is that their values are $\phi_{0}(n), \phi_{1}(n)$, and $\phi_{2}(n)-$ where $n$ indexes iterations - so that the perceived law of motion (PLM) is

$$
\mathrm{y}_{\mathrm{t}}=\phi_{0}(\mathrm{n})+\phi_{1}(\mathrm{n}) \mathrm{y}_{\mathrm{t}-1}+\phi_{2}(\mathrm{n}) \mathrm{u}_{\mathrm{t}}
$$

then the implied unbiased expectation of $\mathrm{y}_{\mathrm{t}+1}$ would be

\footnotetext{
${ }^{7}$ Thus the presence of a policy-provided nominal anchor will rule out nominal indeterminacy but not solution multiplicity.
} 


$$
\phi_{0}(\mathrm{n})+\phi_{1}(\mathrm{n}) \mathrm{y}_{\mathrm{t}}+\phi_{2}(\mathrm{n}) \rho \mathrm{u}_{\mathrm{t}}
$$

Using this last expression in place of $\mathrm{E}_{\mathrm{t}} \mathrm{y}_{\mathrm{t}+1}$ in (1) — which implies that we have temporarily abandoned RE—gives

$$
\mathrm{y}_{\mathrm{t}}=\alpha+\mathrm{a}\left[\phi_{0}(\mathrm{n})+\phi_{1}(\mathrm{n}) \mathrm{y}_{\mathrm{t}}+\phi_{2}(\mathrm{n}) \rho \mathrm{u}_{\mathrm{t}}\right]+\mathrm{cy}_{\mathrm{t}-1}+\mathrm{u}_{\mathrm{t}} .
$$

Thus with rearrangement we have

$$
y_{t}=\left[1-a \phi_{1}(n)\right]^{-1}\left[\alpha+a \phi_{0}(n)+a \phi_{2}(n) \rho u_{t}+c y_{t-1}\right]+u_{t}
$$

as the system's actual law of motion (ALM). Now imagine a sequence of iterations from the PLM to the ALM. Writing the left-hand side of (9) in the form (6) for iteration n+1 implies that

(10b) $\quad \phi_{1}(\mathrm{n}+1)=\left[1-\mathrm{a} \phi_{1}(\mathrm{n})\right]^{-1} \mathrm{c}$

$(10 \mathrm{c}) \quad \phi_{2}(\mathrm{n}+1)=\left[1-\mathrm{a} \phi_{1}(\mathrm{n})\right]^{-1}\left[\mathrm{a} \phi_{2}(\mathrm{n}) \rho+1\right]$.

The issue, then, is whether iterations defined by (10) are such that the $\phi_{\mathrm{j}}(\mathrm{n})$ converge to the $\phi_{\mathrm{j}}$ values in an expression of form (2) as $\mathrm{n} \rightarrow \infty$. If they do, then that solution is said to be iteratively E-stable, and similar investigations can be made for any other RE solutions. Evans (1986) found that in several prominent and controversial examples the MSV solution is iteratively E-stable.

On the basis of results by Marcet and Sargent (1989), Evans (1989) and E\&H (1992) switched attention to E-stability without the "iterative" qualification, defined as follows. Conversion of equations (10) to a continuous form, appropriate as the iteration interval approaches zero, ${ }^{8}$ results in

\footnotetext{
${ }^{8}$ There is also a positive speed-of-adjustment coefficient in each of equations (11), but its magnitude is irrelevant for the convergence issue so is usually (as here) set equal to 1. See, e.g., Evans (1989, p. 299).
} 
(11a) $d \phi_{0}(\mathrm{n}) / \mathrm{dn}=\left[1-\mathrm{a} \phi_{1}(\mathrm{n})\right]^{-1}\left[\alpha+\mathrm{a} \phi_{0}(\mathrm{n})\right]-\phi_{0}(\mathrm{n})$

(11b) $\mathrm{d} \phi_{1}(\mathrm{n}) / \mathrm{dn}=\left[1-\mathrm{a} \phi_{1}(\mathrm{n})\right]^{-1} \mathrm{c}-\phi_{1}(\mathrm{n})$

(11c) $\mathrm{d} \phi_{2}(\mathrm{n}) / \mathrm{dn}=\left[1-\mathrm{a} \phi_{1}(\mathrm{n})\right]^{-1}\left[\mathrm{a} \phi_{2}(\mathrm{n}) \rho+1\right]-\phi_{2}(\mathrm{n})$.

If the differential equation system (11) is such that $\phi_{\mathrm{j}}(\mathrm{n}) \rightarrow \phi_{\mathrm{j}}$ for all $\mathrm{j}$, the solution (2) is E-stable. The crucial feature of this continuous version of the iterative process is that it is intimately related to an adaptive learning process that is modeled as taking place in real time. ${ }^{9}$ For most models of interest, that is, values of parameters analogous to the $\phi_{\mathrm{j}}$ in (2) that are estimated by LS regressions, based on data from periods $t-1, t-2, \ldots, 1$ and used to form expectations in period t, will converge to the actual values in (2) as time passes if equations (11) converge to those values and (2) is dynamically stable (non-explosive). Also, such convergence will not occur if equations (11) do not converge. Thus Estability and LS learnability typically go hand in hand. This result, which is discussed extensively by Evans and Honkapohja $(1999,2001)$, is useful because it is technically much easier, in many cases, to establish E-stability than to establish LS learnability. The latter concept is arguably the more important, in a fundamental sense, as learnability of some type might be regarded as a necessary condition for the relevance of a RE equilibrium.

Some analysts have expressed doubts concerning the relevance of the LS learnability criterion; see, e.g., Buiter and Panigirtzoglu (2002). As a sufficient condition the criterion is not very convincing-obviously, other learning procedures could be considered — but as a necessary condition it seems highly attractive. In this regard, note that the LS learning process assumes that (i) agents are collecting an ever-increasing

\footnotetext{
${ }^{9}$ The E-stability process is itself conceived of as taking place in notional time (meta time).
} 
number of observations on all relevant variables while (ii) the structure is remaining unchanged. Furthermore, (iii) the agents are estimating the relevant unknown parameters with an appropriate estimator in (iv) a properly specified model. Thus if a proposed RE solution is not learnable by the process in question, it would seem rather implausible that it could prevail in practice.

\section{The Taylor Principle}

Let us begin our set of indeterminacy examples by considering the Taylor

principle in a simple version of today's near-canonical monetary policy model. ${ }^{10}$ The latter consists of an optimizing demand relation, the Calvo price-adjustment scheme, and a monetary policy rule for the one-period interest rate:

$$
\begin{array}{ll}
\mathrm{y}_{\mathrm{t}}=\mathrm{E}_{\mathrm{t}} \mathrm{y}_{\mathrm{t}+1}+\mathrm{b}_{0}+\mathrm{b}_{1}\left(\mathrm{R}_{\mathrm{t}}-\mathrm{E}_{\mathrm{t}} \Delta \mathrm{p}_{\mathrm{t}+1}\right)+\mathrm{v}_{\mathrm{t}} & \mathrm{b}_{1}<0 \\
\Delta \mathrm{p}_{\mathrm{t}}=\beta \mathrm{E}_{\mathrm{t}} \Delta \mathrm{p}_{\mathrm{t}+1}+\alpha \mathrm{y}_{\mathrm{t}} & \alpha>0 \\
\mathrm{R}_{\mathrm{t}}=\mathrm{r}+\Delta \mathrm{p}_{\mathrm{t}}+\mu_{1}\left(\Delta \mathrm{p}_{\mathrm{t}}-\pi^{*}\right)+\mu_{2} \mathrm{y}_{\mathrm{t}} &
\end{array}
$$

Here $\mathrm{y}_{\mathrm{t}}, \Delta \mathrm{p}_{\mathrm{t}}$, and $\mathrm{R}_{\mathrm{t}}$ represent the output gap, inflation, and the interest rate while $\mathrm{v}_{\mathrm{t}}$ is a $\mathrm{AR}(1)$ disturbance term, with $\mathrm{AR}$ coefficient $\rho$, incorporating shocks to preferences and the natural-rate (i.e., flexible-price) level of output (treated for simplicity as exogenous). ${ }^{11}$ Also, $\pi^{*}$ is the central bank's inflation target, $r=-b_{0} / b_{1}$ is the average real interest rate, and $\beta$ is the discount factor for private agents $(0<\beta<1)$.

In this setting, the Taylor principle is a condition pertaining to policy parameters $\mu_{1}$ and $\mu_{2}$ that is said to be necessary for desirable behavior of the inflation rate. The

\footnotetext{
${ }^{10}$ Some economists have objected to the term "Taylor principle" on the grounds that the basic idea was recognized earlier by other analysts. But the term has by now been adopted by so many writers that I feel its use is, given Taylor's (1999b) emphasis on the idea, appropriate.

${ }^{11}$ The model is often written with disturbance terms in (13) and/or (14), but they are unnecessary and irrelevant for present purposes. If there is variable government consumption, $\mathrm{v}_{\mathrm{t}}$ will also include its expected change. Other fiscal variables are irrelevant under fairly broad, but not universal, conditions - see Section 7 below.
} 
condition is often expressed for $\mu_{2}=0$, in which case it becomes $\mu_{1}>0$. Then the model can be written as (13) plus

$$
\mathrm{y}_{\mathrm{t}}=\mathrm{E}_{\mathrm{t}} \mathrm{y}_{\mathrm{t}+1}+\mathrm{b}_{0}+\mathrm{b}_{1}\left[\mathrm{r}+\left(1+\mu_{1}\right) \Delta \mathrm{p}_{\mathrm{t}}-\mu_{1} \pi^{*}-\mathrm{E}_{\mathrm{t}} \Delta \mathrm{p}_{\mathrm{t}+1}\right]+\mathrm{v}_{\mathrm{t}}
$$

and the MSV solution is of the form

(16a) $\Delta \mathrm{p}_{\mathrm{t}}=\phi_{10}+\phi_{11} \mathrm{v}_{\mathrm{t}}$

(16b) $\mathrm{y}_{\mathrm{t}}=\phi_{20}+\phi_{21} \mathrm{v}_{\mathrm{t}}$.

Thus $\mathrm{E}_{\mathrm{t}} \Delta \mathrm{p}_{\mathrm{t}}=\phi_{10}+\phi_{11} \rho \mathrm{v}_{\mathrm{t}}$ with $\mathrm{E}_{\mathrm{t}} \mathrm{y}_{\mathrm{t}+1}=\phi_{20}+\phi_{21} \rho \mathrm{v}_{\mathrm{t}}$ and the basic undetermined coefficients procedure implies the following solution:

(17a) $\Delta \mathrm{p}_{\mathrm{t}}=\pi^{*}+\alpha\left[(1-\rho)(1-\rho \beta)-\alpha \mathrm{b}_{1}\left(1+\mu_{1}-\rho\right)\right]^{-1} \mathrm{v}_{\mathrm{t}}$

$$
y_{t}=(1-\beta) \pi^{*} / \alpha+(1-\rho \beta)\left[(1-\rho)(1-\rho \beta)-\alpha b_{1}\left(1+\mu_{1}-\rho\right)\right]^{-1} v_{t}
$$

Suppose, however, that one considers non-MSV solutions of the form

(18a) $\Delta \mathrm{p}_{\mathrm{t}}=\phi_{10}+\phi_{11} \mathrm{v}_{\mathrm{t}}+\phi_{12} \Delta \mathrm{p}_{\mathrm{t}-1}+\phi_{13} \mathrm{v}_{\mathrm{t}-1}$

(18b) $\mathrm{y}_{\mathrm{t}}=\phi_{20}+\phi_{21} \mathrm{v}_{\mathrm{t}}+\phi_{22} \Delta \mathrm{p}_{\mathrm{t}-1}+\phi_{23} \mathrm{v}_{\mathrm{t}-1}$

Then going through the same steps as before one finds that relations (18) admit a multiplicity of RE solutions. One of these is the MSV solution given by (17) but there are others as well. Their dynamic properties clearly depend upon $\phi_{12}$, whose value is given by the quadratic equation $\beta \phi_{12}^{2}-\phi_{12}\left(1+\beta-\alpha b_{1}\right)+\left[1-\alpha b_{1}\left(1+\mu_{1}\right)\right]=0$. Given our structural sign restrictions, one root of the latter is invariably greater than 1 , but the other root will lie between 0 and 1 , yielding a second stable solution, if $\mu_{1}<0$. Thus there is multiple-solution indeterminacy if the Taylor-principle condition does not hold.

Is this result — two stable RE solutions —-something to be concerned about? My proposed answer is "not necessarily." Suppose that there were some convincing reason to believe that one of the solutions would prevail and that it is one that will not support 
"sunspot" terms. Then the existence of one or more additional solutions would not pose a practical problem for policy conducted according to the rule (14). Or, to approach the issue in a different fashion, let us ask: what undesirable real-world phenomenon is supposed to result as a consequence of the existence of two stable solutions? Clearly it is not explosive inflation, as some discussions of the failure of the Taylor principle would seem to suggest. Instead, it seems that it is the possibility of sunspot solutions and their associated variability that is of principal concern in situations of indeterminacy. ${ }^{12}$ But, as stated above, we must consider whether such a solution is likely to prevail in the case under discussion.

In that regard, there is in my opinion a genuine problem that prevails when $\mu_{1}<0$. It is that neither of the RE solutions is learnable, in the least-squares sense described above. There is therefore no good reason to believe that either of the RE solutions would provide a plausible description of the behavior of inflation and the output gap, even if the simple model provided by (12) and (13) were adequate.

How does one carry out E-stability analysis for the two stable solutions found for the model (13)(15)? Given its simple structure, a starting point might be to write the model in first order form, i.e., as

$$
\mathrm{x}_{\mathrm{t}}=\mathrm{AE}_{\mathrm{t}} \mathrm{x}_{\mathrm{t}+1}+\mathrm{u}_{\mathrm{t}},
$$

where $x_{t}$ is the column vector $\left[\Delta p_{t} y_{t}\right]^{\prime}$ and $u_{t}$ is the relevant vector of exogenous driving variables, assumed to be first-order autoregressive with stable parameter matrix R. ${ }^{13}$ Then one could examine the eigenvalues of A and apply results developed by Evans $(1986,1989)$ and generalized by E\&H $(2001$, Ch. 10). These indicate that the MSV

\footnotetext{
${ }^{12}$ Woodford (1986) has shown that under certain conditions there is an if-and-only-if relationship between local indeterminacy (with a continuum of solutions) and existence of sunspot equilibria.

${ }^{13}$ Constant terms are neglected in this discussion for simplicity.
} 
solution is E-stable if and only if both eigenvalues of A have real parts less than 1 and, in addition, all four products of the eigenvalues of $\mathrm{A}$ and $\mathrm{R}$ have real parts less than 1 . Implementation of this procedure is tedious, however, and furthermore does not provide results pertaining to all of the non-MSV solutions. ${ }^{14}$ Fortunately, thorough analysis has been provided by the recent papers of Bullard and Mitra (2002) and Honkapohja and Mitra (2001). Together they indicate that, in the setting at hand, learnability of the MSV solution obtains if and only if $\mu_{1}>0$, i.e., if the Taylor principle is respected by the policy rule. ${ }^{15}$ In addition Honkapohja and Mitra (2001, p. 19) establish that non-MSV equilibria are not learnable in the model at hand - their Example 1—when the Taylor principle is not satisfied. Honkapohja and Mitra suggest that this result provides an important argument—one that differs from the suggestion of Clarida, Gali, and Gertler (2000) — in support of the idea that it is crucial for interest rate policy rules to satisfy the Taylor principle.

The foregoing discussion constitutes the main substance of this section, but it may be of interest to illustrate the analysis for an even simpler version of the model. Accordingly, let us retain the demand relation (12) but replace the Calvo priceadjustment equation (13) with the assumption that prices adjust promptly, thereby keeping output continually at its flexible-price level (i.e., keeping $\left.\mathrm{y}_{\mathrm{t}}=0\right) .{ }^{16}$ Then the system (13) (15) reduces to $0=\mathrm{b}_{1}\left[\left(1+\mu_{1}\right) \Delta \mathrm{p}_{\mathrm{t}}-\mu_{1} \pi^{*}-\mathrm{E}_{\mathrm{t}} \Delta \mathrm{p}_{\mathrm{t}+1}\right]+\mathrm{v}_{\mathrm{t}}$. Clearly, the latter can be written as $\Delta \mathrm{p}_{\mathrm{t}}=\mu_{1} \pi^{*}\left(1+\mu_{1}\right)^{-1}+\left(1+\mu_{1}\right)^{-1} \mathrm{E}_{\mathrm{t}} \Delta \mathrm{p}_{\mathrm{t}+1}-\mathrm{b}_{1}{ }^{-1} \mathrm{v}_{\mathrm{t}}$, which is of form (19). Then the relevant eigenvalue condition for E-stability of the MSV solution is simply $\left(1+\mu_{1}\right)^{-1}<1$, provided that $\mathrm{v}_{t}$ is white noise or has a positive $\mathrm{AR}(1)$ parameter. Thus this

\footnotetext{
${ }^{14}$ There might exist "sunspot" solutions in addition to the two solutions of form (18) mentioned above.

${ }_{15}^{15}$ See Proposition 2 of Bullard and Mitra (2002).

${ }^{16}$ An equivalent system has been studied by Woodford (2002, Ch. 2).
} 
special case illustrates more generally the point of this section, that the Taylor principle is of importance because its non-satisfaction leads to a situation in which all RE solutions fail to be learnable. ${ }^{17}$

\section{Inflation Forecast Targeting}

Next we turn to a second type of multiple-solution indeterminacy, which can arise when the central bank's interest rate policy rule responds to an expected future inflation rate, rather than the actual current inflation rate. This case was introduced by Woodford (1994), and has since been discussed by many analysts including Bernanke and Woodford (1997), Kerr and King (1996), King (2000), Carlstrom and Fuerst (2001), and Bullard and Mitra (2002). Svensson (1997) — who suggests that the relevant form of policy behavior should not be termed inflation forecast targeting but instead "responding to inflation forecasts"-refers to the potential problem as "the Woodford warning."

To illustrate the problem, let us again consider the canonical system (12)-(14), but with $\mathrm{E}_{\mathrm{t}} \Delta \mathrm{p}_{\mathrm{t}+1}$ replacing $\Delta \mathrm{p}_{\mathrm{t}}$ in the policy rule (14). Then with $\mu_{2}=0$ equation (15) becomes (15') $\mathrm{y}_{\mathrm{t}}=\mathrm{E}_{\mathrm{t}} \mathrm{y}_{\mathrm{t}+1}+\mathrm{b}_{0}+\mathrm{b}_{1}\left[\mathrm{r}+\mu_{1} \mathrm{E}_{\mathrm{t}} \Delta \mathrm{p}_{\mathrm{t}+1}\right]+\mathrm{v}_{\mathrm{t}}$. Again there is a MSV solution of form (16) and also solutions of form (18) based on roots to a quadratic equation for $\phi_{12}$. In this case the quadratic is $\beta \phi_{12}{ }^{2}-\phi_{12}\left(1+\beta+\alpha b_{1} \mu_{1}\right)$ $+1=0$. Thus the roots are $\phi_{12}=\left[d \pm \sqrt{d^{2}-4 \beta}\right] / 2 \beta$, where $d=1+\beta+\alpha b_{1} \mu_{1}$. These roots will be imaginary if $0<\mu_{1}<\mu_{1}^{\mathrm{c}}=\left[2 \beta^{0.5}+1+\beta\right] /\left(-\mathrm{b}_{1} \alpha\right)$, in which case the MSV solution will be the only real solution. But if $\mu_{1}<0$ or $\mu_{1}>\mu_{1}^{\mathrm{c}}$, then there will be multiple stable

\footnotetext{
${ }^{17}$ This situation can be overturned by the adoption of certain rather extreme fiscal policy rules; see Section 7 below.
} 
solutions. $^{18}$

To assess the E-stability and LS learnability of the MSV and non-MSV solutions we again draw on results of Bullard and Mitra (2002) and Honkapohja and Mitra (2001). Proposition 5 of the former indicates that the MSV solution is E-stable if and only if $\mu_{1}>$ 0 , showing that the Taylor principle is again relevant. For the non-MSV solutions of form (18), moreover, Honkapohja and Mitra (2001, p. 20) find that they are not E-stable for any value of $\mu_{1}$. Thus the LS learnability criterion lends some support to the suggestion that the MSV solution is the only plausible RE solution even in cases referred to by the Woodford warning.

This support is not complete, for Honkapohja and Mitra (2001, pp. 19-20) find that another form of non-explosive RE solution is E-stable and learnable. Specifically, they find that non-explosive resonant frequency sunspot equilibria can exist and be Estable in the case under discussion. Indeed, they state that this result "strengthens the worries concerning the indeterminacy problems with forward looking interest rules pointed out" by Bernanke and Woodford (1997).

I would argue, however, that these resonant frequency sunspot equilibria should be viewed as mathematical curiosa, not as plausible paths relevant for economic analysis of actual economies. My argument is based on the nature of the resonant frequency sunspot process. It presumes that there is a finite-state Markov process for an exogenous sunspot variable, with fixed transition probabilities and with specified effects on the system's endogenous variables that result from the different sunspot states. Then for the

\footnotetext{
${ }^{18}$ Carlstrom and Fuerst (2001) obtain some quite different results, which they attribute to an altered timing assumption regarding the money or asset balances that provide transaction-facilitating services: start of period versus end of period. Actually, however, the crucial change in their analysis is in the optimizing IS function comparable to (12). That no such change is necessitated by use of start-of-period money balances is shown in various writings, including McCallum (2001a, pp. 20-21).
} 
resonant frequency sunspot solutions to exist, there must be an eigenvalue of the matrix of state transition probabilities that is exactly equal to the inverse of an eigenvalue of a matrix such as A in (19) for the model at hand. ${ }^{19}$ But if there is no causal connection between the sunspot disturbance process (i.e., the transition probabilities) and the model's behavioral parameters, then the requisite condition will hold only on a parameter space of measure zero. Thus the plausibility of such sunspot equilibria is at least one or two orders of magnitude smaller than that for sunspots of the more familiar type that permits their generating process to be any martingale difference process. ${ }^{20}$

In sum, then, I would argue that the Honkapohja and Mitra (2001) analysis actually provides more support for the view that only MSV equilibria are learnable in the model at hand - that is, the canonical model with inflation forecast targeting - than for the view that non-MSV equilibria can be E-stable and learnable.

\section{Zero-Lower-Bound Deflation Trap}

The third topic to be investigated is prompted by recent papers by Benhabib, Schmitt-Grohe, and Uribe (2001, 2002), Buiter and Panigirtzoglu (2002), and Alstadheim and Henderson (2002), among others, which argue that recognition of the existence of a zero lower bound (ZLB) on nominal interest rates leads to the conclusion that inflation targeting rules — or ones of the more general Taylor type — are likely to fail. The alleged reason is that the existence of a ZLB implies that RE solutions to standard optimizing models with Taylor rules are not globally unique and that one solution, likely to be attained, involves a deflationary liquidity trap.

\footnotetext{
${ }^{19}$ See Honkapohja and Mitra (2001, Proposition 2).

${ }^{20}$ At the time of the conference, both Michael Woodford and George Evans announced that the necessary condition will be less stringent in a nonlinear version of the model. Even so, I would suggest that resonantfrequency sunspots are much less plausible than those of the more familiar type considered in Honkapohja and Mitra's Proposition 3.
} 
For analysis of this topic, consider again the canonical model (12)-(14) but with the flexible price assumption $\mathrm{y}_{\mathrm{t}}=0$ replacing, only for simplicity, the Calvo price adjustment equation (13). Also let $\mu_{2}=0$. Then the model reduces to

$$
0=\mathrm{b}_{0}+\mathrm{b}_{1}\left[\mathrm{r}+\left(1+\mu_{1}\right) \Delta \mathrm{p}_{\mathrm{t}}-\mu_{1} \pi^{*}-\mathrm{E}_{\mathrm{t}} \Delta \mathrm{p}_{\mathrm{t}+1}\right]+\mathrm{v}_{\mathrm{t}}
$$

so the MSV solution is of the form

$$
\Delta \mathrm{p}_{\mathrm{t}}=\phi_{0}+\phi_{1} \mathrm{v}_{\mathrm{t}}
$$

implying $\mathrm{E}_{\mathrm{t}} \Delta \mathrm{p}_{\mathrm{t}+1}=\phi_{0}+\phi_{1} \rho \mathrm{v}_{\mathrm{t}}$. Then substitution into (20) and application of the undetermined coefficient procedure yields the requirement that

$$
0=b_{0}+b_{1}\left[r-\mu_{1} \pi^{*}+\left(1+\mu_{1}\right)\left(\phi_{0}+\phi_{1} v_{t}\right)-\left(\phi_{0}+\phi_{1} \rho v_{t}\right)\right]+v_{t}
$$

holds identically for all realizations of $\mathrm{v}_{\mathrm{t}}$. The latter implies unique values for $\phi_{0}$ and $\phi_{1}$ that, with $r=-b_{0} / b_{1}$, yield the MSV solution

$$
\Delta \mathrm{p}_{\mathrm{t}}=\pi^{*}-\left[\mathrm{b}_{1}\left(1+\mu_{1}-\rho\right)\right]^{-1} \mathrm{v}_{\mathrm{t}}
$$

Therefore, since the unconditional expectation $\mathrm{E}\left(\mathrm{v}_{\mathrm{t}}\right)=0$, it is clear that $\mathrm{E} \Delta \mathrm{p}_{\mathrm{t}}=\pi^{*}$, i.e., the long-run average rate of inflation given by the MSV solution is equal to the target value specified by the central bank's policy rule.

There is, however, another solution that satisfies the usual conditions for a RE equilibrium. Consider the solution form

$$
\Delta \mathrm{p}_{\mathrm{t}}=\phi_{0}+\phi_{1} \mathrm{v}_{\mathrm{t}}+\phi_{2} \Delta \mathrm{p}_{\mathrm{t}-1}+\phi_{3} \mathrm{v}_{\mathrm{t}-1}
$$

which implies $\mathrm{E}_{\mathrm{t}} \Delta \mathrm{p}_{\mathrm{t}+1}=\phi_{0}+\phi_{1} \rho \mathrm{v}_{\mathrm{t}}+\phi_{2}\left(\phi_{0}+\phi_{1} \mathrm{v}_{\mathrm{t}}+\phi_{2} \Delta \mathrm{p}_{\mathrm{t}-1}+\phi_{3} \mathrm{v}_{\mathrm{t}-1}\right)+\phi_{3} \mathrm{v}_{\mathrm{t}}$. Then the undetermined coefficient conditions are

$$
\begin{aligned}
& \mathrm{b}_{1}\left[-\mu_{1} \pi^{*}+\left(1+\mu_{1}\right) \phi_{0}-\phi_{0}\left(1+\phi_{2}\right)\right]=0 \\
& \mathrm{~b}_{1}\left[\left(1+\mu_{1}\right) \phi_{1}-\phi_{1} \rho-\phi_{2} \phi_{1}-\phi_{2} \phi_{3}\right]+1=0 \\
& \phi_{2}^{2}=\phi_{2}\left(1+\mu_{1}\right)
\end{aligned}
$$




$$
\mathrm{b}_{1}\left[\left(1+\mu_{1}\right) \phi_{3}-\phi_{2} \phi_{3}\right]=0 .
$$

Thus there are two possibilities for $\phi_{2}$, namely, 0 and $1+\mu_{1}$. If the former is selected we have the MSV solution as given in (23), but if $\phi_{2}=1+\mu_{1}$ is designated as relevant, the solution becomes

$$
\Delta \mathrm{p}_{\mathrm{t}}=-\mu_{1} \pi^{*}+\left(1+\mu_{1}\right) \Delta \mathrm{p}_{\mathrm{t}-1}+\phi_{1} \mathrm{v}_{\mathrm{t}}+\left[\left(1-\mathrm{b}_{1} \rho \phi_{1}\right) /\left(1+\mu_{1}\right)\right] \mathrm{v}_{\mathrm{t}-1}
$$

for any $\phi_{1}$. Clearly, with $\mu_{1}>0$ the latter is explosive. Consequently, if the system "begins" with $\Delta \mathrm{p}_{\mathrm{t}-1}>\pi^{*}$ then inflation will increase explosively, and if the startup value is below $\pi^{*}$ then $\Delta \mathrm{p}_{\mathrm{t}}$ will have a tendency to approach $-\infty$, according to (26) and as illustrated in Figure 1 (which abstracts from the stochastic element provided by $\mathrm{v}_{\mathrm{t}}$ ).

But the last statement ignores the existence of a ZLB on the nominal interest rate. In the flexible price system at hand, the latter translates into a lower bound on $\mathrm{E}_{\mathrm{t}} \Delta \mathrm{p}_{\mathrm{t}+1}$; we have the restriction $\mathrm{E}_{\mathrm{t}} \Delta \mathrm{p}_{\mathrm{t}+1} \geq-\mathrm{r}$. Thus if the system begins with $\Delta \mathrm{p}_{\mathrm{t}-1}<\pi^{*}$, inflation cannot behave as specified by (26). Instead, the alleged outcome is that $\Delta \mathrm{p}_{\mathrm{t}} \rightarrow-\mathrm{r}$, which corresponds to $R_{t} \rightarrow 0$. Crucially, there is no violation of a transversality condition, as there would be if $\Delta \mathrm{p}_{\mathrm{t}}$ were to approach $-\infty$. So in this case the policy rule (14) fails to stabilize inflation around its target value, $\pi^{*}$. This is the failure of the Taylor rule proposed and emphasized in the papers mentioned above.

Again, however, the agenda here is to consider the E-stability of the two solutions (23) and (26). For both, the analysis for this form of model is provided by Evans (1986, 1989), who shows that the MSV solution (23) is E-stable and learnable, whereas a solution such as (26) is not E-stable or learnable. ${ }^{21}$

\footnotetext{
${ }^{21}$ If one were to believe that the non-MSV solution (26) is relevant, then he would need to consider what happens if the system begins with $\Delta \mathrm{p}_{\mathrm{t}-1}>\pi^{*}$, since there is no transversality condition to rule out $\Delta \mathrm{p}_{\mathrm{t}} \rightarrow \infty$.
} 
The foregoing statement applies literally to the model without the ZLB constraint. But the latter does not affect the analysis, which is local in nature, of the MSV solution. Then for the non-MSV solution, we need to replace (20) with the ZLB constraint. This can be done by rewriting (20) so as to pass through the point $(-r,-r)$ and inserting a parameter that controls its slope. Then the ZLB constraint would be imposed by letting the slope approach zero. Thus the analysis would be as before, but with a slope of less than 1.0 at the non-MSV solution, which would imply E-instability.

A more satisfying approach might be to recognize that the lower bound on the nominal interest rate is actually the consequence of a decreasing net marginal benefit, via facilitation of transactions, provided by holdings of money. ${ }^{22}$ Then the relevant functional form would be as illustrated in Figure 2. There the MSV solution is at point A and the liquidity trap at point B. For this continuous nonlinear case, the analysis in Chapter 11 of E\&H (2001) indicates that the MSV solution is E-stable and the trap solution is not, at least with a small variance for $\mathrm{v}_{\mathrm{t}}$. Accordingly, while a ZLB situation may arise if the target inflation rate is set too low, the indeterminacy-based mechanism described above does not seem plausible.

\section{Fiscal Theory of the Price Level}

The fourth and final topic to be considered is the fiscal theory of the price level, for which the most important references are Woodford (1994, 1995, 2001, 2002), Sims (1994), Cochrane (1998), and Kocherlakota and Phelan (1999)—with Buiter (1999) and McCallum (1999a, 2001a) as the main critics. The relationship to solution multiplicity is different in this case, as will be seen in the development below. Before undertaking that

\footnotetext{
${ }^{22}$ See, e.g., McCallum (2001b).
} 
development, however, it should be emphasized just how drastically unorthodox and counter-traditional the fiscal theory of price level determination is. Specifically, it does not suggest merely that fiscal as well as monetary policy stances are significant for price level behavior; instead it features a leading example in which the price level moves over time in a manner that mimics the path of government bonds and is entirely unlike the path of the money stock. Accordingly, it is not the case that the argument involves fiscal behavior that drives an accommodative monetary authority, as when rapid base money growth is adopted to finance a fiscal deficit. Indeed, it is this drastic aspect of the fiscal theory that has made it a subject of great interest. ${ }^{23}$

What is the policy issue that is posed by the fiscal theory of the price level? The two main suggestions are apparently (i) that the behavior of the price level and other macro variables may be very different than predicted by orthodox monetary analysis and/or (ii) that coordination between monetary and fiscal policy authorities is necessary for satisfactory macroeconomic performance. To consider these suggestions, let us begin with an extremely simple formulation. Specifically, suppose that the (per capita) money demand function for a closed economy is of the textbook form

$$
\mathrm{m}_{\mathrm{t}}-\mathrm{p}_{\mathrm{t}}=\mathrm{c}_{0}+\mathrm{c}_{1} \mathrm{y}_{\mathrm{t}}+\mathrm{c}_{2} \mathrm{R}_{\mathrm{t}}+\mathrm{v}_{\mathrm{t}} \quad \mathrm{c}_{1}>0, \mathrm{c}_{2}<0,
$$

where $\mathrm{m}_{\mathrm{t}}, \mathrm{p}_{\mathrm{t}}$, and $\mathrm{y}_{\mathrm{t}}$ are logs of the (base) money stock, price level, and output (income) for period $t$, while $\mathrm{R}_{\mathrm{t}}$ denotes a one-period nominal interest rate. The disturbance $\mathrm{v}_{\mathrm{t}}$ is taken for simplicity to be white noise. It is well known that there are rigorous dynamic

\footnotetext{
${ }^{23}$ In this regard, an important point is that the type of model typically utilized in the literature's analysis is not of the overlapping generations type, in which the Ricardian equivalence proposition is known to failimplying that tax changes will affect price level behavior. Instead, the model is basically of the SidrauskiBrock type, in which Ricardian equivalence results are normally obtained, i.e., results implying that bondfinanced tax changes have no effect on the price level or other macroeconomic variables of primary interest. In such a setting, fiscalist positions are truly striking.
} 
general equilibrium models with optimizing agents that will justify (27) as a linear approximation to a combination of implied Euler equations (first-order optimality conditions). Furthermore, assume that the economy is one in which output and the real rate of interest are constant over time so that (27) reduces to

$$
\mathrm{m}_{\mathrm{t}}-\mathrm{p}_{\mathrm{t}}=\gamma+\alpha\left(\mathrm{E}_{\mathrm{t}} \mathrm{p}_{\mathrm{t}+1}-\mathrm{p}_{\mathrm{t}}\right)+\mathrm{v}_{\mathrm{t}} \quad \alpha=\mathrm{c}_{2}<0,
$$

which is the familiar Cagan specification for money demand. Also suppose that the quantity of (base) money is kept constant by the central bank, so that

$$
\mathrm{m}_{\mathrm{t}}=\mathrm{m} .
$$

Then (28) and (29) plus rational expectations govern the behavior of $\mathrm{p}_{\mathrm{t}}$ for time periods $\mathrm{t}=1,2, \ldots$. It is possible that the structure was different prior to period 1 .

In this setting, the MSV solution for $\mathrm{p}_{\mathrm{t}}$ is of the form

$$
\mathrm{p}_{\mathrm{t}}=\phi_{0}+\phi_{\mathrm{1}} \mathrm{v}_{\mathrm{t}}
$$

so $\mathrm{E}_{\mathrm{t}} \mathrm{p}_{\mathrm{t}+1}=\phi_{0}$ and the usual analysis yields

$$
\text { (31) } \mathrm{p}_{\mathrm{t}}=\mathrm{m}-\gamma-\mathrm{v}_{\mathrm{t}} \mathrm{/}(1-\alpha) \text {. }
$$

Thus, $\mathrm{p}_{\mathrm{t}}$ fluctuates randomly around a constant value and if money demand shocks were absent we would have $\mathrm{p}_{\mathrm{t}}=\mathrm{m}-\gamma$.

But while (31) gives the traditional, "monetarist," bubble-free solutions for this model, there are other expressions as well that satisfy the model with RE. To see this, conjecture a solution of the form

$$
p_{t}=\psi_{0}+\psi_{1} p_{t-1}+\psi_{2} v_{t}+\psi_{3} v_{t-1}
$$

instead of $p_{t}=\phi_{0}+\phi_{1} \mathrm{v}_{\mathrm{t}}$. Then working through the same type of analysis as before, one finds that the relevant UC conditions are 


$$
\begin{aligned}
& 0=\alpha \psi_{1}^{2}+(1-\alpha) \psi_{1} \\
& 0=\alpha \psi_{1} \psi_{2}+\alpha \psi_{3}+(1-\alpha) \psi_{2}+1 \\
& 0=\alpha \psi_{1} \psi_{3}+(1-\alpha) \psi_{3} \\
& \mathrm{~m}=\gamma+\alpha \psi_{0}+\alpha \psi_{1} \psi_{0}+(1-\alpha) \psi_{0} .
\end{aligned}
$$

By inspection we see that the first of these has two roots $\psi_{1}{ }^{(1)}=0$ and $\psi_{1}{ }^{(2)}=(\alpha-1) / \alpha$. If the former is the relevant root, then the same solution as in (31) is obtained. But if $\psi_{1}{ }^{(2)}$ is relevant, then $\psi_{3}=-1 / \alpha$ and $\psi_{0}=(\mathrm{m}-\gamma) / \alpha$ while any value of $\psi_{2}$ is possible. So an infinity of solution paths is in this case consistent with the model. Note, moreover, that $\psi_{1}^{(2)}=(\alpha-1) / \alpha>1.0$, so most of these solution paths are explosive. One such path is illustrated in Figure 3, where the random component is suppressed.

There are, however, additional variables and conditions in a fully specified model of the economy under consideration. In particular, let $\mathrm{B}_{\mathrm{t}+1}$ denote the (per capita) quantity of one-period government bonds purchased in $\mathrm{t}$, with each bond purchased at the price $1 /\left(1+R_{t}\right)$ and redeemed in $t+1$ for one unit of money. Then a full-fledged optimizing analysis would require that

$$
\lim _{j \rightarrow \infty} E_{t} \beta^{j}\left(M_{t+j}+B_{t+j}\right) / P_{t+j}=0,
$$

i.e., that a transversality condition pertaining to real financial wealth must be satisfied. Here $\beta$ is a typical agent's discount factor, $\beta=1 /(1+\rho)$, with $\rho>0$ so that $0<\beta<1$. (Note that $\rho$ has a different meaning here than in previous sections.)

We are now prepared to describe the fiscalist theory in this setting. With government bonds recognized, we can write the consolidated government budget constraint (GBC) in per capita terms as 


$$
P_{t}\left(g_{t}-t x_{t}\right)=M_{t+1}-M_{t}+\left(1+R_{t}\right)^{-1} B_{t+1}-B_{t}
$$

where $g_{t}$ and $\mathrm{tx}_{\mathrm{t}}$ are real government purchases and (lump sum) tax collections, respectively. In real terms, this constraint could then be expressed as

$$
\mathrm{g}_{\mathrm{t}}-\mathrm{tx}_{\mathrm{t}}=\left(\mathrm{M}_{\mathrm{t}+1}-\mathrm{M}_{\mathrm{t}}\right) / \mathrm{P}_{\mathrm{t}}+\left(1+\mathrm{R}_{\mathrm{t}}\right)^{-1}\left(\mathrm{P}_{\mathrm{t}+1} / \mathrm{P}_{\mathrm{t}}\right) \mathrm{b}_{\mathrm{t}+1}-\mathrm{b}_{\mathrm{t}}, \quad \mathrm{t}=1,2, \ldots,
$$

where $b_{t}=B_{t} / P_{t}$. Note the mixed notation being utilized: $b_{t}=B_{t} / P_{t}$ whereas $m_{t}=\log M_{t}$ and $\mathrm{p}_{\mathrm{t}}=\log \mathrm{P}_{\mathrm{t}}$

Now consider (36) when $\mathrm{M}_{\mathrm{t}}$ and thus $\mathrm{m}_{\mathrm{t}}$ are constant. Also let the random shock $\mathrm{V}_{\mathrm{t}}$ be absent so that $\mathrm{P}_{\mathrm{t}+1}$ is correctly anticipated in $\mathrm{t}$ and suppose that fiscal policy aims for a constant surplus $t x_{t}-g_{t}=s>0$ with $g_{t}=g$. Then with the real rate of interest on bonds $r_{t}$ defined by $1+r_{t}=\left(1+R_{t}\right) /\left(1+\pi_{t+1}\right)$, where $\pi_{t+1}=\left(P_{t+1}-P_{t}\right) / P_{t}$, and with $r_{t}=\rho$, as would be implied by optimizing behavior in the absence of shocks, the government budget constraint becomes

$$
b_{t+1}=(1+\rho) b_{t}+(1+\rho)\left(g_{t}-t_{t}\right) \quad t=1,2, \ldots
$$

But since $1+\rho>1$, if $g_{t}-t x_{t}$ is constant the last equation reveals a strong tendency for $b_{t}$ to explode as time passes. As $t$ grows without limit, $b_{t}$ approaches growth at the rate $\rho$, i.e., behaves like $(1+\rho)^{t}$. Thus the transversality condition (34) tends to be violated since growth of $b_{t}$ just offsets the shrinkage of $\beta^{t}=1 /(1+\rho)^{t}$, yielding a limit that is positive.

In fact, in this case there are two paths for $b_{t}$ that, with $g_{t}-t x$ constant, will satisfy (37) and also (32)(33)(34) for $t=1,2, \ldots$. One of these obtains if the value $b_{1}$ equals $-(1+\rho)(g-t x) / \rho$, for then (37) implies that

$$
\begin{aligned}
\mathrm{b}_{2} & =(1+\rho)[-(1+\rho)(\mathrm{g}-\mathrm{tx}) / \rho]+(1+\rho)(\mathrm{g}-\mathrm{tx}) \\
& =(1+\rho)(\mathrm{g}-\mathrm{tx})[-(1+\rho) / \rho+1]=-(1+\rho)(\mathrm{g}-\mathrm{tx}) / \rho
\end{aligned}
$$

and that same value prevails in all succeeding periods. Here $b_{1}=B_{1} / P_{1}$, and $B_{1}$ is the 
number of nominal government bonds outstanding at the beginning of the initial period, $t=1$. Thus if the price level in this first period, $P_{1}$, adjusts to equal the value $P_{1}=$ $\mathrm{B}_{1} \rho /(1+\rho)(\mathrm{tx}-\mathrm{g})$, then condition (34) as well as (37) will be satisfied. Indeed, this is what the fiscalist theory predicts: that $\mathrm{P}_{1}$ adjusts relative to $\mathrm{B}_{1}$ and $\mathrm{tx}-\mathrm{g}>0$ so as to satisfy the individual agents' optimality condition (34).

What about the necessary condition for money demand? In this regard, the fiscalist answer is that although the path just described will not conform to the $\mathrm{p}_{\mathrm{t}}=\mathrm{m}-\gamma$ solution implied by (31), it can and will satisfy the alternative solution $\mathrm{p}_{\mathrm{t}}=$ $[(\alpha-1) / \alpha] p_{t-1}+(m-\gamma) / \alpha$ for all $t=2,3, \ldots$ The price level $P_{1}$, and thus $\mathrm{p}_{1}$, is determined by $B_{1}$ and the value of $b_{1}$ necessary to satisfy (34), with subsequent $P_{t}$ and $p_{t}$ values being given by (32) with $\psi_{1}=(\alpha-1) / \alpha$. The price level explodes as time passes, despite the constant value of $\mathrm{M}_{\mathrm{t}}$, but all of the model's equilibrium conditions are satisfied nevertheless. Since $\mathrm{P}_{t}$ and $\mathrm{B}_{\mathrm{t}}$ are growing at the same (explosive) rate, while $\mathrm{M}_{t}$ is constant, the outcome is rightfully regarded as highly "fiscalist." 24

But let us consider a second path of $b_{t}$ that will, with $g$ - tx constant, satisfy the TC (34) as well as (32), (33), and (37). It is one in which $b_{t+1}=0$ for all $t=1,2, \ldots$ Then, clearly, (34) will be satisfied with $\mathrm{B}_{\mathrm{t}+1}=0$ and in that case places no constraint on $P_{t}$ values. Thus these are free to obey $p_{t}=m-\gamma$, as in the special case of (32)-(33) given by (31). Therefore this solution is the orthodox or monetarist solution.

It remains to be considered how the $\mathrm{GBC}$ (37) can be satisfied with this solution, i.e., with $\mathrm{B}_{\mathrm{t}+1}=0$ for $\mathrm{t}=1,2, \ldots$ and $\mathrm{tx}_{\mathrm{t}}-\mathrm{g}>0$. The explanation is as follows. In a

\footnotetext{
${ }^{24}$ There is a serious problem, however, with this solution if $B_{1}$ is such that the implied value of $P_{1}$ is smaller than $\mathrm{P}^{*}=\mathrm{Me}^{-\gamma}$. In this case the fiscalist equilibrium does not exist because $\mathrm{P}_{\mathrm{t}}$ approaches 0 , leading to violation of the transversality condition (34). Also, if $\mathrm{tx}-\mathrm{g}<0$, then a negative price level would be required for satisfaction of (37) by the assumed value of $b_{1}$.
} 
market economy, it is not appropriate to specify fiscal policy as controlling both $g_{t}$ and $t_{t}$ (with an $M_{t}$ path given) because with such a policy (37) could imply that the number of bonds sold to the private sector is greater than the number demanded. Thus the analysis needs to distinguish between bond supply $\mathrm{B}^{\mathrm{S}}{ }_{t+1}$ and bond demand $\mathrm{B}^{\mathrm{D}}{ }_{\mathrm{t}+1}$, and policy is appropriately specified in terms of $\mathrm{M}_{\mathrm{t}}, \mathrm{g}_{\mathrm{t}}$, and $\mathrm{B}_{\mathrm{t}+1}^{\mathrm{S}}$ with one relevant equilibrium condition being $\mathrm{B}^{\mathrm{D}}{ }_{t+1} \leq \mathrm{B}^{\mathrm{S}}{ }_{t+1}$. In the case under consideration, the planned value of $\mathrm{tx}_{\mathrm{t}}$ $\mathrm{g}>0$ reflects $\mathrm{B}_{\mathrm{t}+1}^{\mathrm{S}}$, whereas the realized values involve $\mathrm{B}_{\mathrm{t}+1}=\mathrm{B}_{\mathrm{t}+1}^{\mathrm{D}}=0$ and $\mathrm{tx}_{\mathrm{t}}-\mathrm{g}=0$. The $\mathrm{tx}$ - $\mathrm{g}$ values realized are smaller than planned because real revenues from bond sales are larger-zero, rather than the planned negative value, which is $-\rho b_{1} /(1+\rho)$. It is not surprising that some such adjustment is needed since the experiment at hand involves monetary $\left(\mathrm{M}_{\mathrm{t}}\right)$ and fiscal $\left(\mathrm{g}_{\mathrm{t}}\right.$ and $\left.\mathrm{B}_{\mathrm{t}+1}^{\mathrm{S}}\right)$ policies that are set independently and exogenously. The monetarist and fiscalist solutions reflect two different ways by which these potentially conflicting policies can be reconciled.

In sum, we end up with two RE solutions that represent two competing hypotheses regarding price level behavior in an economy such as the one under study. The crucial issue, then, is which of the two solutions provides the better guide to reality, i.e., to price level behavior in actual economies? In previous writings (McCallum 1999a, 2001a) I have argued that the traditional equilibrium is the "fundamentals" or "bubblefree" solution provided by the MSV solution concept, whereas the fiscalist solution represents a bubble solution. I have suggested that this is a plausible reason-in addition to existing empirical evidence- for preferring the former, but for many analysts that 
argument may not be persuasive. ${ }^{25}$ Accordingly, we now consider the E-stability and learnability properties of the two solutions.

As it happens, that comparison is easy for the case at hand. Write the model as

$$
\mathrm{p}_{\mathrm{t}}=[\alpha /(\alpha-1)] \mathrm{E}_{\mathrm{t}} \mathrm{p}_{\mathrm{t}+1}+(\mathrm{m}-\gamma) /(1-\alpha)+[1 /(\alpha-1)] \mathrm{v}_{\mathrm{t}}
$$

and note that with $\alpha<0$, the coefficient on $\mathrm{E}_{\mathrm{t}} \mathrm{p}_{\mathrm{t}+1}$ lies between 0 and 1 . Thus the eigenvalue for A in equation (19) is smaller than 1, and the results described at the end of Section 4 pertain: the MSV (monetarist) solution is E-stable and learnable, while the nonMSV (fiscalist) solution is not. Note that although (39) does not explicitly refer to the fiscal variable $\mathrm{B}_{\mathrm{t}}$, it does not exclude the possibility that the fiscal solution can be learned, since $\psi_{1}$ can adjust toward $(\alpha-1) / \alpha$ and $\psi_{0}$ can adjust to the value, $\log \left[\mathrm{B}_{1} \rho /(1+\rho)(\mathrm{tx}-\mathrm{g})\right]-[(\alpha-1) / \alpha] \mathrm{p}_{0}$, that makes $\mathrm{p}_{1}$ equal the fiscalist value described above. $^{26}$

The foregoing result is for a highly special case; can it be generalized in any way? With respect to functional form of the money demand equation, the answer is yes. Ignoring stochastic terms, the linear model that we have used to this point can be represented graphically as in Figure 3. There the traditional MSV solution is that $\mathrm{p}_{\mathrm{t}}=\mathrm{p}^{*}$, at the intersection point, for each $t=1,2, \ldots$ The fiscalist solution, by contrast, implies $\mathrm{p}_{t}$ values given by paths such as that of the thin line in Figure 3. Most of the literature has, of course, utilized explicit optimizing models that imply an analogous diagram as shown in Figure 4, where there is a nonlinear $\mathrm{P}_{\mathrm{t}}$ to $\mathrm{P}_{\mathrm{t}+1}$ mapping that has an positive but increasing slope. Do the results above carry over to such models? Although there are

\footnotetext{
${ }^{25}$ For example, Woodford (2001, p. 701) argues that "what constitutes a 'bubble equilibrium' is often in the eye of the beholder...."

${ }^{26}$ This argument can be extended to the case with stochastic disturbances.
} 
some qualifications, the answer is basically "yes." The main point is that E-stability is a local concept, so that conclusions pertaining to the MSV solution in Figure 3 apply to models of the type in Figure 4. Thus the MSV solution is E-stable. Indeed, very recent analysis by $\mathrm{E} \& \mathrm{H}(2002 \mathrm{~b})$ obtains the same result in an explicitly nonlinear model, and also obtains results as above for the non-MSV solutions.

The foregoing discussion represents our basic application of the paper's argument to the fiscal theory of the price level; it improves upon the argument of McCallum (2001a) significantly by adoption of the learnability criterion. It is clear, however, that the policy specification considered is quite special, so there remains a need to extend the learnability analysis to a broader class of policy regimes. The most well-known specification of such regimes is that of Leeper (1991), in which the monetary authority adjusts a one-period nominal interest rate instrument according to a rule of the form

$$
\mathrm{R}_{\mathrm{t}}=\mu_{0}+\left(1+\mu_{1}\right) \Delta \mathrm{p}_{\mathrm{t}}+\theta_{\mathrm{t}}
$$

while simultaneously the fiscal authority holds $\mathrm{g}_{\mathrm{t}}=0$ and implements a (lump-sum) tax rule of the form

$$
\mathrm{tx}_{\mathrm{t}}=\tau_{0}+\tau_{1} \mathrm{~b}_{\mathrm{t}}+\zeta_{\mathrm{t}}
$$

Here $\theta_{\mathrm{t}}$ and $\zeta_{\mathrm{t}}$ are white noise policy shocks. Leeper (1991) classifies monetary policy as "active" if $\left|\left(1+\mu_{1}\right) \beta\right|>1$ and as "passive" otherwise, and classifies fiscal policy as active if $\left|\beta^{-1}-\tau_{1}\right|>1$ and passive otherwise.

Very recently, E\&H (2002b) have conducted analysis based on policy rules (40) and (41), sensibly focusing on cases in which $1+\mu_{1}>0$ and $\tau_{1}>0$. Using a linearized version of their extended model, E\&H (2002b) find that there are solutions of two types that correspond in several ways to the monetarist and fiscalist solutions discussed above. 
For example, in the monetarist solution the inflation rate depends only upon a constant and $\theta_{\mathrm{t}}$, the current monetary policy shock, while the fiscalist solution has the inflation rate also depending on the previous period's real bond stock. For the most part, the monetarist solution is E-stable and LS learnable when monetary policy is active and fiscal policy passive, whereas the fiscalist solution is E-stable and LS learnable when monetary policy is passive and fiscal policy active. When non-explosive, the fiscalist solution does not imply outcomes inconsistent with beliefs of monetarist economists [e.g., Brunner and Meltzer (1972)] since there is no major discrepancy between the paths of the price level and the money stock. ${ }^{27}$ There is also a small region of the policy parameter space that leads to E-stability with explosive solutions, but it seems questionable whether one of these should be regarded as an equilibrium since explosive behavior of the real bond stock would seem to imply failure of a transversality condition that would be necessary for private optimality.

From a practical perspective, emphasis should, I believe, be given to the region in which $\left(1+\mu_{1}\right) \beta>1$ and $\rho<\tau_{1}<1+\rho$, for the following reason. The former condition represents the Taylor principle in the model at hand, while the latter calls for taxes to be levied at a rate that would be large enough to make $b_{t}$ non-explosive, in the absence of any government revenue from money creation, and yet not so large as to imply that taxes in a single period would reduce government debt by more than the amount outstanding. That is, a positive fraction of outstanding bonds would be retired in each period. ${ }^{28}$ Then

\footnotetext{
${ }^{27}$ Whether this is a MSV solution remains to be determined.

${ }^{28}$ It seems peculiar that Leeper (1991) would designate such behavior as representing "passive" fiscal policy, since it represents feedback responses designed to stabilize the stock of bonds outstanding. More generally, Leeper's policy rule specification seems somewhat inappropriately designed for analysis of the issue emphasized by Woodford (1995), namely, whether price level determination is basically monetary or fiscal in nature. To represent the traditional monetary point of view, it would seem preferable to specify
} 
the $\mathrm{E} \& \mathrm{H}$ results indicate that, over this entire region, the monetarist solution is E-stable (and the fiscalist solution is not). This result seems especially important in that it indicates that well behaved (and orthodox) outcomes, as given by the MSV solution, will result when monetary and fiscal policy rules are each sensible on their own terms, with no overt coordination or dependence by either policy authority on the behavior of the other. $^{29}$

\section{Concluding Remarks}

The foregoing pages have discussed four current topics in monetary policy analysis, each of which hinges in some way on the possibility of multiple solutions that satisfy the usual definition of rational expectations. In two of these cases, ${ }^{30}$ analysis of the adaptive learnability of the multiple solutions suggests that only one of them is a viable candidate for a RE equilibrium when account is taken of the need for corrections to occur in response to small departures away from that equilibrium. Thus it is suggested that the dangers alleged to prevail, in these cases, are not ones with which actual policymakers need to be concerned. In the case of the Taylor principle, by contrast, it has been argued that the consequences of policy behavior that violates the principle are genuinely undesirable, since all of the RE equilibria fail to be learnable. Finally, our analysis of the simplest version of the fiscal theory of the price level suggests that the traditional solution is learnable and the fiscalist solution is not. With more general specifications of the policy rules, the outcome is not so clear-cut. It appears doubtful,

monetary policy in terms of a rule governing responses of a narrow monetary aggregate (e.g., base money) to inflation or price-level departures from target values. This contention does not involve any denial, of course, that most actual central banks employ an interest rate instrument.

${ }^{29}$ The result does not imply, evidently, that there are no parameter regions in which the fiscalist solution (as classified by E\&H (2002b)) is learnable.

${ }^{30}$ The forecast targeting and ZLB trap cases. 
nevertheless, that any equilibrium, in which price level and money stock behavior are very different, is learnable.

More generally, these examples suggest that learnability, not indeterminacy, should be viewed as the relevant issue for policy-oriented theoretical analysis of monetary policy. More contentiously, it might be argued that RE solution multiplicity should be viewed basically as a mathematical curiosity, stemming from an insufficiently specific definition of rational expectations, rather than as a substantive problem for actual policy makers. Whatever the conclusion drawn, a unified treatment would of course provide a more attractive argument than the foregoing catalog of examples. I hope to be able to produce one in the future. 


\section{References}

Alstadheim, R., and D.W. Henderson (2002) "Price-Level Determinacy, the Zero Lower Bound on the Interest Rate, and the Liquidity Trap," Working Paper.

Benhabib, J., S., Schmitt-Grohe, and M. Uribe (2001) “The Perils of Taylor Rules,” Journal of Economic Theory 96, 40-69.

_ _ _ and ___ (2002) “Avoiding Liquidity Traps,” Journal of Political Economy 110, 535-563.

Bernanke, B.S., and M. Woodford (1997) "Inflation Forecasts and Monetary Policy," Journal of Money, Credit, \& Banking 24, 653-684.

Brunner, K., and A.H. Meltzer (1972) “Money, Debt, and Economic Activity,” Journal of Political Economy 80, 951-977.

Buiter, W.H. (1999) "The Fallacy of the Fiscal Theory of the Price Level," NBER Working Paper 7302.

Buiter, W.H., and N. Panigirtzoglu (2002) "Overcoming the Zero Bound on Nominal Interest Rates with Negative Interest on Currency: Gesell's Solution,” Working Paper, European Bank for Reconstruction and Development.

Bullard, J., and K. Mitra (2002) “Learning About Monetary Policy Rules,” Journal of Monetary Economics 49, 1105-1129.

Cagan, P. (1956) "The Monetary Dynamics of Hyperinflation," in Studies in the Quantity Theory of Money, ed. M. Friedman (Chicago: Univ. of Chicago Press).

Calvo, G.A. (1983) “Staggered Prices in a Utility Maximizing Framework,” Journal of Monetary Economics 12, 383-398. 
Carlstrom, C.T., and T.S. Fuerst (2001), “Timing and Real Indeterminacy in Monetary Models," Journal of Monetary Economics 47, 285-298.

Clarida, R., J. Gali, and M. Gertler (1999) “The Science of Monetary Policy: A New Keynesian Perspective,” Journal of Economic Literature 37, 1661-1707. , and ___ (2000) "Monetary Policy Rules and Macroeconomic

Stability: Evidence and Some Theory," Quarterly Journal of Economics 15, 14780.

Cochrane, J.H. (1998) “A Frictionless View of U.S. Inflation,” NBER Macroeconomics

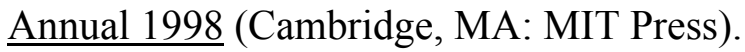

DeCanio, S.J. (1979) "Rational Expectations and Learning from Experience,” Quarterly Journal of Economics 93, 47-57.

Evans, G.W. (1985) “Expectational Stability and the Multiple Equilibrium Problem in Linear Rational Expectations Models," Quarterly Journal of Economics 100, 1217-1233. (1986) “Selection Criteria for Models with Non-Uniqueness," Journal of Monetary Economics 18, 147-157. (1989) “The Fragility of Sunspots and Bubbles," Journal of Monetary

Economics 23, 297-317.

Evans, G.W., and S. Honkapohja (1992) "On the Robustness of Bubbles in Linear RE Models," International Economic Review 33, 1-14. and (1999) "Learning Dynamics," in $\underline{\text { Handbook of }}$ Macroeconomics, J.B. Taylor and M. Woodford, eds. (Amsterdam: NorthHolland Pub. Co.) 
and (2001) Learning and Expectations in Macroeconomics.

(Princeton: Princeton Univ. Press). and (2002a) "Expectational Stability of Stationary Sunspot

Equilibria in a Forward-looking Linear Model," Working Paper, January. and (2002b) "Policy Interaction, Learning, and the Fiscal

Theory of Prices," Working Paper, July.

Gurley, J.G., and E.S. Shaw (1960) Money in a Theory of Finance. Brookings Institution, Washington, DC.

Honkapohja, S., and K. Mitra (2001) “Are Non-Fundamental Equilibria Learnable in Models of Monetary Policy?” Working Paper, University of Helsinki.

Johnson, H.G. (1962) “Monetary Theory and Policy,” American Economic Review 52, $325-384$.

Kerr, W., and R.G. King (1996) "Limits on Interest Rate Rules in the IS Model," Federal Reserve Bank of Richmond Economic Quarterly 82 (Spring), 47-76.

King, R.G. (2000) “The New IS-LM Model: Language, Logic, and Limits,” Federal Reserve Bank of Richmond Economic Quarterly 86 (Summer), 45-103.

Kocherlakota, N., and C. Phelan (1999) "Explaining the Fiscal Theory of the Price Level,” Federal Reserve Bank of Minnesota Quarterly Review 23(4), 14-23. Leeper, E.M. (1991) “Equilibria Under 'Active' and 'Passive’ Monetary and Fiscal Policies," Journal of Monetary Economics 27, 129-147.

Marcet, A., and T. J. Sargent (1989) “Convergence of Least Squares Learning Mechanisms in Self-Referential Linear Stochastic Models," Journal of Economic Theory 48, 337-368. 
McCallum, B.T. (1983) “On Non-Uniqueness in Rational Expectations Models: An Attempt at Perspective," Journal of Monetary Economics 11, 139-168. (1986) "Some Issues Concerning Interest Rate Pegging, Price Level Determinacy and the Real Bills Doctrine," Journal of Monetary Economics 17, 135-150.

(1999a) "Issues in the Design of Monetary Policy Rules," in $\underline{\text { Handbook }}$

in Macroeconomics, J.B. Taylor and M. Woodford, eds. (Amsterdam: NorthHolland Pub. Co.).

(1999b) "Role of the Minimal State Variable Criterion in Rational

Expectations Models," in International Finance in Turmoil: Essays in Honor of

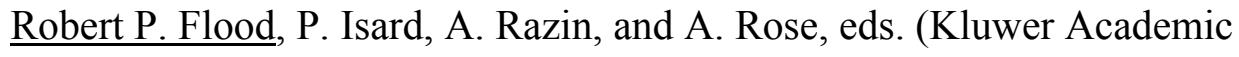

Publishers, Boston). Also International Tax and PublicFinance 6, 621-639. (2001a) "Indeterminacy, Bubbles, and the Fiscal Theory of Price Level

Determination," Journal of Monetary Economics 47, 19-30. (2001b) "Monetary Policy Analysis in Models without Money," Federal

Reserve Bank of St. Louis Review 83 (July/August), 145-160.

McCallum, B.T., and E. Nelson (1999) "Performance of Operational Policy Rules in an

Estimated Semi-Classical Structural Model." In Taylor (1999), pp.15-45.

Patinkin, D. (1949) “The Indeterminacy of Absolute Prices in Classical Economic Theory," Econometrica 17, 1-27. (1965) Money, Interest, and Prices, $2^{\text {nd }}$ ed. Harper and Row. Sims, C.A. (1994) “A Simple Model for the Study of the Determination of the Price Level and the Interaction of Monetary and Fiscal Policy," Economic Theory 4, 381-99. 
Svensson, L.E.O. (1997) "Inflation Forecast Targeting: Implementing and Monitoring Inflation Targets," European Economic Review 41, 1111-1146.

Taylor, J.B. (1993) “Discretion Versus Policy Rules in Practice,” Carnegie-Rochester Conference Series on Public Policy 39, 195-214. . (1999a) Monetary Policy Rules. Univ. of Chicago Press for NBER, Chicago. . (1999b) “A Historical Analysis of Monetary Policy Rules," in Taylor (1999a).

Woodford, M. (1986) "Stationary Sunspot Equilibria,” Working Paper. (1994a) "Nonstandard Indicators for Monetary Policy: Can Their Usefulness Be Judged From Forecasting Regressions?” In Monetary Policy, G.N. Mankiw, ed. University of Chicago Press for NBER. (1994b) "Monetary Policy and Price-Level Determinacy in a Cash-in-

Advance Economy," Economic Theory 4, 345-380. (1995) "Price-Level Determinacy Without Control of a Monetary

Aggregate," Carnegie-Rochester Conference Series on Public Policy 43, 1-46. (2001) “Fiscal Requirements for Price Stability,” Journal of Money, Credit, and Banking 33, 671-728. (2002) Interest and Prices. Manuscript, Princeton University. 
Figure 1

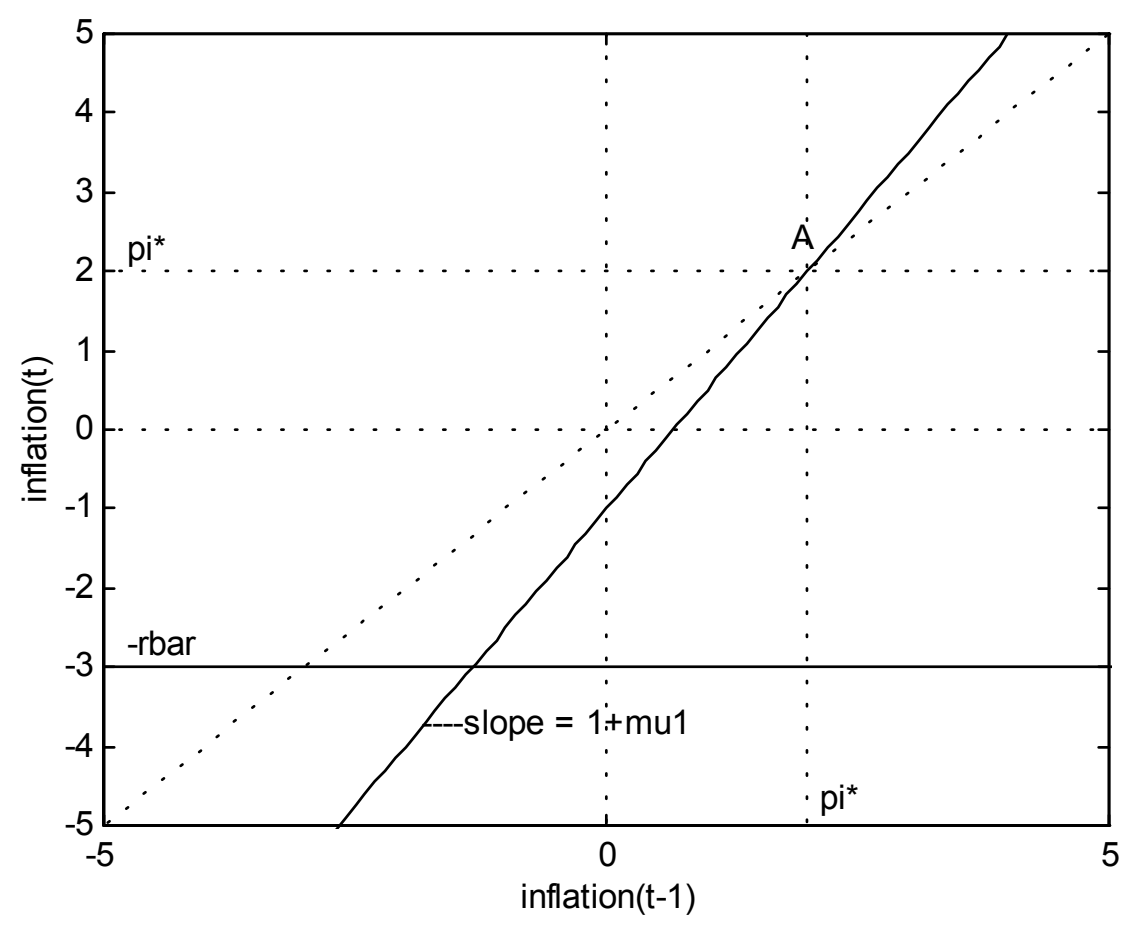

Figure 2

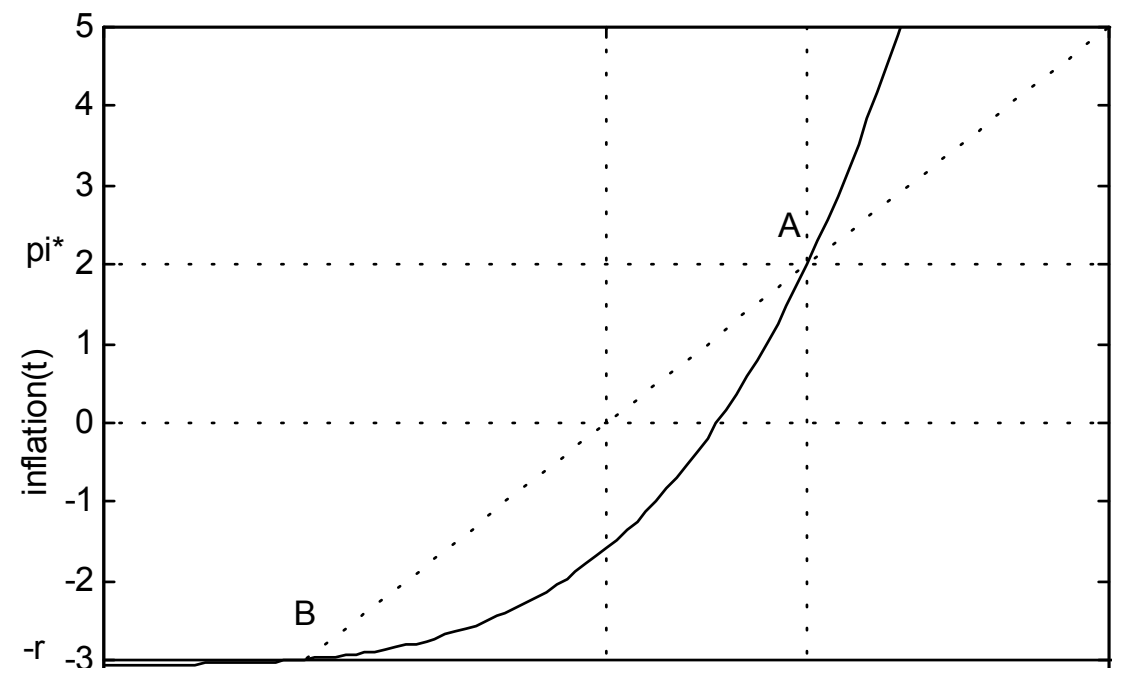


Figure 3

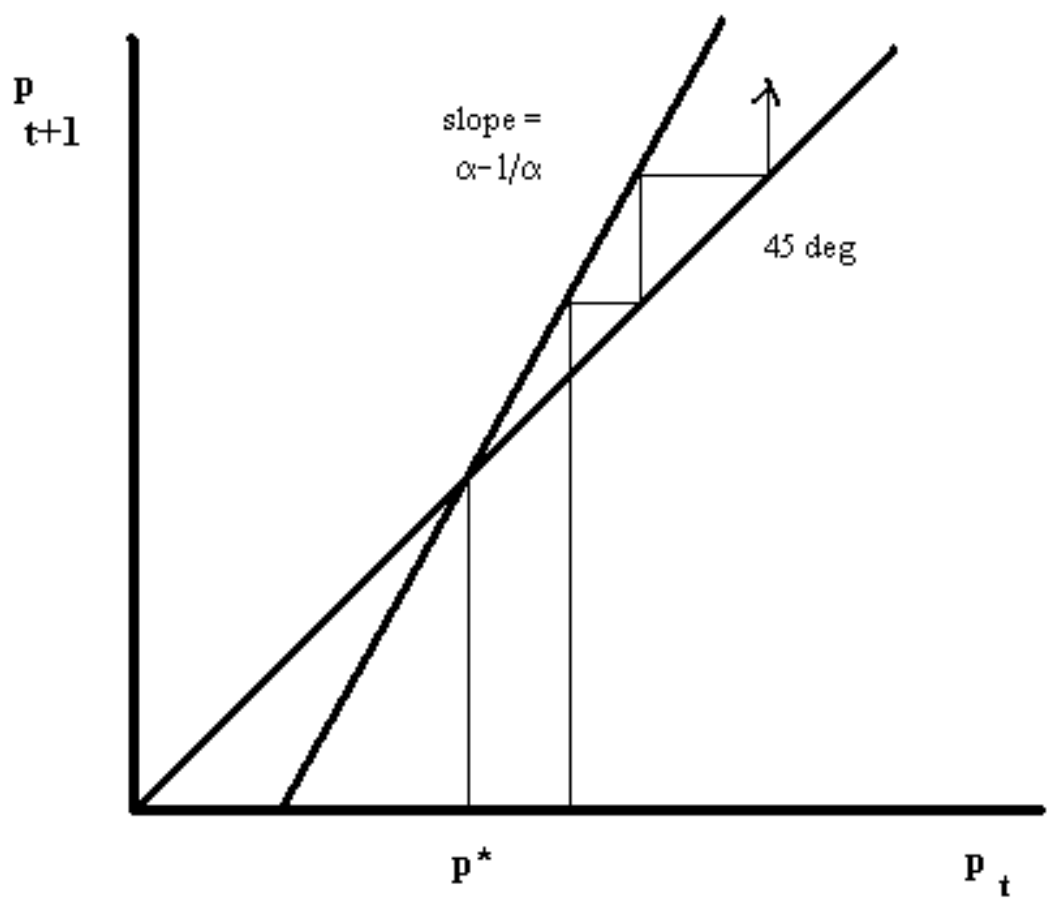

Figure 4

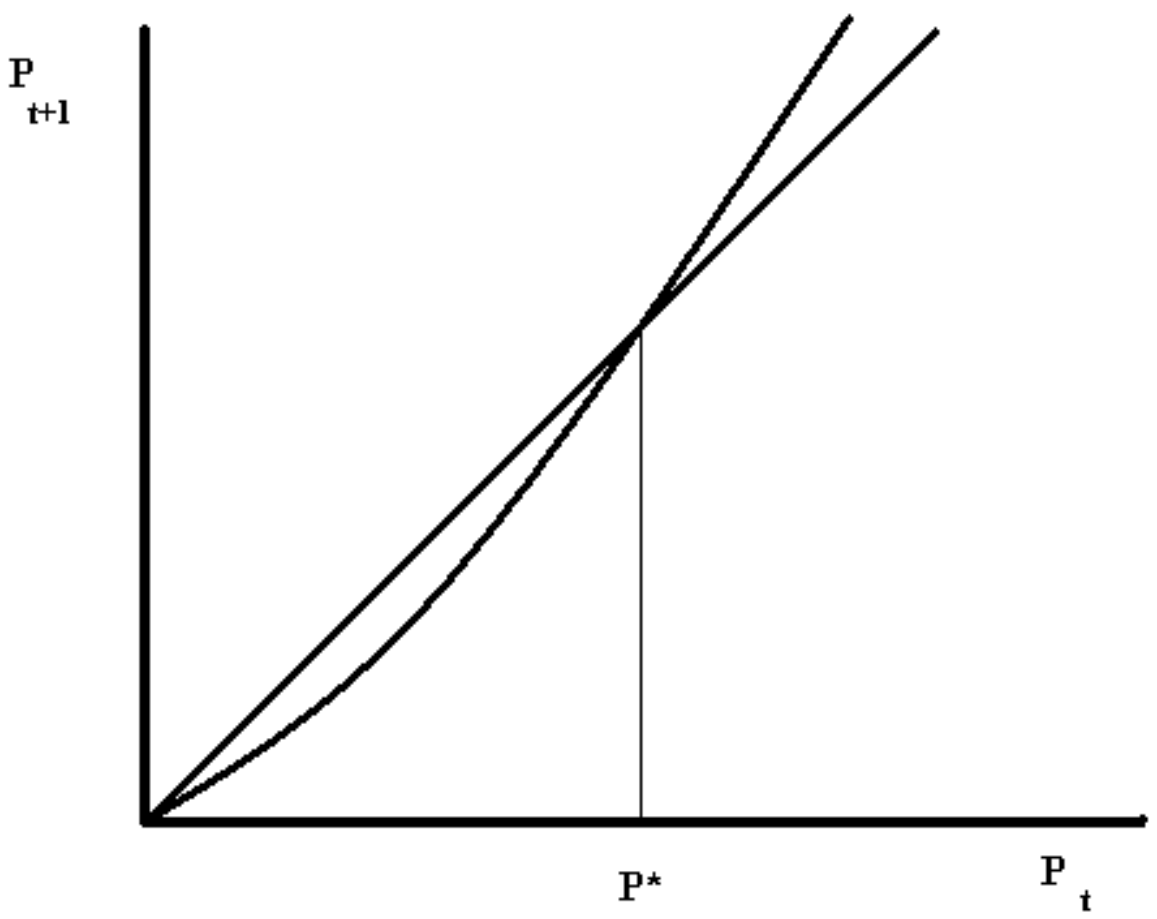

